\title{
MEASURES OF DOWNSIDE RISK UNDER CONDITIONS OF DOWNTURN IN THE REAL ESTATE MARKET
}

\author{
Rafał Wolski, PhD. \\ Department of Economics of Industry and Capital Markets \\ Universiy of Lodz \\ e-mail:rwolski@uni.lodz.pl
}

\begin{abstract}
Some authors suggest that the use of standard deviation as a measure of total risk for returns on real estate leads to risk overestimation, as the classical Markowitz model does not account for the skewness of financial data, thus making the results unreliable. According to the available literature, risk calculated on the basis of standard semideviation may actually better reflect the nature of property investment. However, in this context, the question of whether or not this measure will lead to risk underestimation at a time of a downturn in the real estate market, resulting in inadequate investment decisions aggravating investor losses arises. Therefore, the present paper presents portfolios constructed using either classical risk measures or measures based on "downside deviations" of rates of return. The results of investment in these portfolios are analyzed.
\end{abstract}

Keywords: downside risk measures, standard semideviation, skewness of financial data, portfolio theory, real estate.

\section{JEL Classification: G11.}

Citation: Wolski R., (2013), "Measures of downside risk under conditions of downturn in the real estate market", Real Estate Management and Valuation, vol. 21, no. 3, pp. 81-87.

DOI: $10.2478 /$ remav-2013-0029.

\section{Introduction}

In the face of the current challenges to the economy and the destabilized financial markets, seeking investment opportunities that would provide an alternative to stocks and bonds is of particular relevance. This problem seems particularly important in Poland, where real estate does not constitute a very popular type of investment (WOLSKI, ZALECZNA, 2011). A search for alternative investments implies the necessity to revalue the portfolio and make some choices concerning asset allocation.

Portfolio management has been discussed in literature, especially in the theory proposed by MARKOWITZ (1952, 1959). However, portfolio analysis tends to focus primarily on investment in shares, so its application to real estate raises questions as to the nature of these assets. The real estate market offers assets which vary in terms of attractiveness and characteristics (SIVITANIDES, 1998, p. 159). Markowitz's classical approach to portfolio analysis adopted a normal distribution of returns on the analyzed investments. Thus, standard deviation was assumed to be an appropriate measure of risk, while the selection of portfolio elements was based on the analysis of correlation between the assets.

The choice of investments with different correlation coefficients led to diversification and obtaining a better relationship between returns and risk. However, this approach is criticized by some, especially in light of research showing that financial data have a skewed rather than normal distribution, in contrast to Markowitz's assumption (SIVITANIDES, 1998 p.160, SING, ONG, 2000, CHENG, 2005). Additionally, since the 1950s, some authors have proposed that investors are mostly interested 
in the probability of failure as a measure of investment (un)attractiveness (ROY, 1952, ATWOOD, 1985, BIGMAN, 1996). Data skewness undermines the adequacy of risk measures using standard deviation. In such a situation, it has been suggested that standard semideviation may be a better measure of risk, as it reflects only the standard deviation of those returns that are below the expected reference rate of return. Thus, risk measured with standard semideviation represents the probability of not reaching the initially expected return (HARLOW, RAO, 1989, TSE, UPPAL, 1993, KUCHARSKA-STASIAK, 2006, p. 115).

Taking into consideration data skewness, the use of standard semideviation eliminates risk overestimation. If risk were overestimated, then the expected level of risk would be miscalculated, leading to an inadequate selection of an investment portfolio, which would be too conservative. On the other hand, risk overestimation may affect the portfolio by removing safe assets which would otherwise effectively diversify investments. Still, one could argue that the downside approach is not free from flaws, either. The question arises of what will happen if financial data do have a distribution close to normal in a given period of time? As literature shows, such a situation is possible (TARCZYŃSKI, MOJSIEWICZ, 2001, p. 51). Then, investment risk measured with standard semideviation could produce inaccurate results.

Discrepancies between the results obtained using different measures are likely to be most pronounced under conditions of sudden market changes, such as the emergence of a price bubble or a sudden plunge in asset value in its aftermath. If risk measured with standard semideviation ignores returns higher than the expected rate then, at a time of dynamic growth, semideviation may indicate a low level of risk. However, assets quickly gaining in value during a bull market equally promptly decline in a bear market. As the probability of a future event is estimated based on past observations, investor expectations are shaped by historical levels of risk. Still, risk changes over time (FERSON, KANDEL, STAMBAUGH, 1987, p. 201, COOPER, PRIESTLEY, 2009, p. 2802). Thus, risk assessment may be flawed, especially if this risk is measured with standard semideviation.

\section{Research}

In order to check whether or not risk measured with standard semideviation gives inaccurate results, the main research hypothesis is: in a bear market, total risk measured with the standard deviation of returns makes it possible to construct an investment portfolio with a higher rate of return than that constructed based on analysis of standard semideviation. Furthermore, it is assumed that a dynamic growth of share prices and their subsequent dynamic decline influence the distribution of returns, causing it not to be negatively skewed, which may affect the accuracy of calculating risk with standard semideviation. Thus, an auxiliary research hypothesis is that at a time of dynamic price growth returns will be characterized by a positively skewed distribution, while at a time of decline they will be skewed negatively.

\subsection{Data}

Investments in real estate may be of physical (tangible) or financial nature. Physical investments include land, buildings, and the expansion or modernization of existing buildings. Financial investments consist of purchasing shares in companies investing in the real estate market, purchasing investment units of funds specialized in indirect or direct investments in the real estate market, and purchasing mortgage-based securities, e.g., covered bonds (Kucharska-Stasiak2006, p.109).

Analysis of the real estate market in Poland is extremely difficult due to a lack of adequate databases. Therefore, stock exchange data concerning the real estate market, that is, the prices of units of the closed funds ARKAFRN12, BPHFIZSN, and KBCISNFIZ listed on the Warsaw Stock Exchange and investing in properties, the WIG-CONSTRUCTION industry index, and the WIG20 stock index, are used as a benchmark. Returns on 52-week Treasury bills were used to calculate the risk free rate of return. The selection of assets was determined by the study period (June 14, 2006 to February 18, 2009). Daily data were used. The study period was chosen so as to meet the principles underlying the research hypotheses. From June 2006 to October 29, 2007, the WIG20 index was on the rise, while on February 18, 2009 it started to decline. Both the WIG-Construction index and the investment funds exhibited slightly different periods of bull and bear markets. When examining data skewness, observations were adjusted to particular cases in order to always study a bull market and subsequently, after reaching maximum values, a bear market. 


\section{Methodology}

The auxiliary hypothesis was verified by testing the distribution of all assets over two periods. The periods were selected individually each time, in accordance with the approach described above. In total, 10 samples with rates of return were created; two samples for each type of asset. After testing the auxiliary research hypothesis, the main hypothesis was verified. Two investment portfolios were constructed and optimized using the criterion of minimizing total risk. The optimum portfolio structure was analyzed for all the assets available in the sample. The study period was divided into two subperiods: a bull market and a bear market. Comparing the returns obtained from the portfolios, it was determined which risk measure (that based on standard semideviation or on standard deviation) had better effects on making investment decisions. Portfolios were constructed based on two levels of risk. Historical risk was calculated with two measures based on bull market samples. This risk was used to determine expected risk and construct an appropriate portfolio. Subsequently, the portfolio structure was tested based on data from bear market periods, thus determining the portfolios actually realized based on the previous analysis. This approach was based on the assumption that at the peak of the bull market the investors expect it to continue, not anticipating a market change, which certainly influences the structure of their portfolios. By comparing the results that could have been achieved using expected risk and actual risk, conclusions were drawn as to the verification of the main hypothesis.

\section{Results}

The auxiliary hypothesis assumed that bull markets were characterized by positive skewness and bear markets by negative skewness. All assets were analyzed, and the results are presented in Table 1.

Table 1

Skewness and distribution of returns in bull and bear markets

\begin{tabular}{|c|c|c|c|c|c|c|c|}
\hline & & \multirow[b]{2}{*}{ Skewness } & \multirow[b]{2}{*}{ Kurtosis } & \multicolumn{4}{|c|}{ Tests for normality of distribution } \\
\hline & & & & $\begin{array}{c}\text { Kolmogorov- } \\
\text { Smirnov test } \\
\text { (a) }\end{array}$ & df & $\begin{array}{l}\text { Shapiro- } \\
\text { Wilk test }\end{array}$ & df \\
\hline \multirow{2}{*}{ WIG20 } & hossa & 0.060 & 0.764 & $0.050 *$ & 347 & $0.991^{*}$ & 347 \\
\hline & bessa & -0.094 & 1.436 & $0.060^{*}$ & 324 & $0.983^{*}$ & 324 \\
\hline \multirow{2}{*}{$\begin{array}{c}\text { WIG- } \\
\text { Construction }\end{array}$} & hossa & -0.139 & 1.580 & $0.064^{*}$ & 216 & $0.977^{*}$ & 216 \\
\hline & bessa & -0.007 & 1.298 & $0.046^{*}$ & 455 & $0.988^{*}$ & 455 \\
\hline \multirow{2}{*}{ ARKAFRN12 } & hossa & 1.357 & 3.457 & $0.155^{*}$ & 159 & $0.889^{*}$ & 159 \\
\hline & bessa & -0.436 & 10.322 & $0.125^{*}$ & 512 & $0.866^{*}$ & 512 \\
\hline \multirow{2}{*}{ BPHFIZSN } & hossa & 2.343 & 7.295 & $0.194^{*}$ & 158 & $0.752^{*}$ & 158 \\
\hline & bessa & -0.274 & 6.846 & $0.114^{*}$ & 513 & $0.882^{*}$ & 513 \\
\hline \multirow{2}{*}{ KBCISNFIZ } & hossa & 12.362 & 160.999 & $0.504^{*}$ & 175 & $0.085^{*}$ & 175 \\
\hline & bessa & -9.568 & 112.379 & $0.516^{*}$ & 401 & $0.128^{*}$ & 401 \\
\hline
\end{tabular}

(a) with Lilliefor's significance correction

* hypothesis concerning normal distribution of the sample was rejected

Source: own work.

The analysis shows that only WIG-Construction did not exhibit positive skewness during a bull market (the value of skewness for that period is negative, but close to zero). Normal distribution was not observed in any of the cases. Normality of distribution was tested using the Kolmogorov-Smirnov test with Lilliefor's significance correction and the Shapiro-Wilk test. In all cases, the results were similar.

Figures 1 and 2 show histograms for return distributions. The graphic presentation of the distributions confirms the statistical results. The histograms reveal skewness and the absence of normal distribution. Furthermore, a high kurtosis indicates a distribution that is more "tapering" than normal distribution, which is also visible in the diagrams. 


\section{VERSITA}
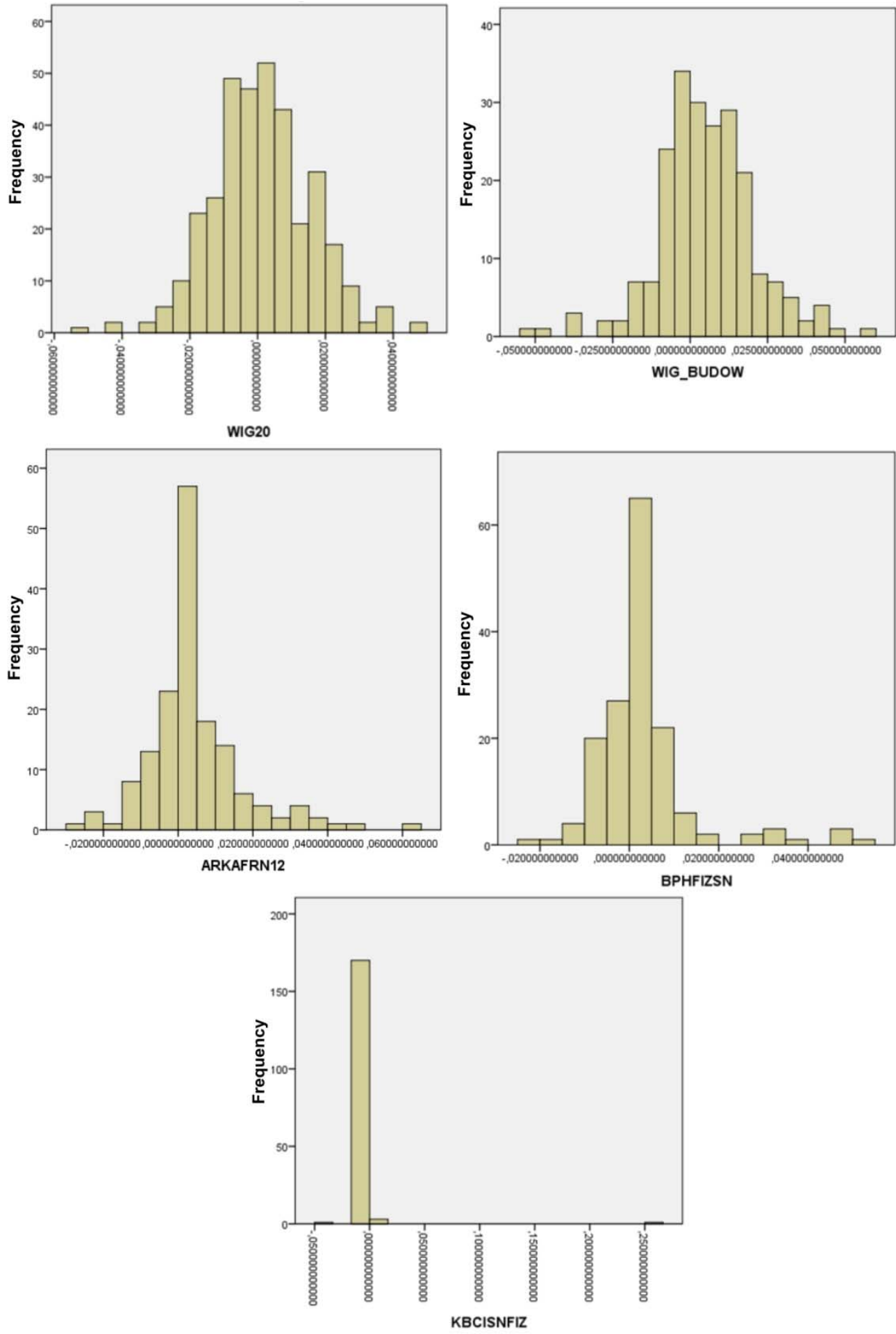

Fig. 1. Distribution of returns in a bull market. Source: own work.

The main hypothesis was verified by empirical examination of whether or not risk measured with standard semideviation misleads investors, giving them an unfounded sense of security in a situation of dynamic growth of asset prices. 

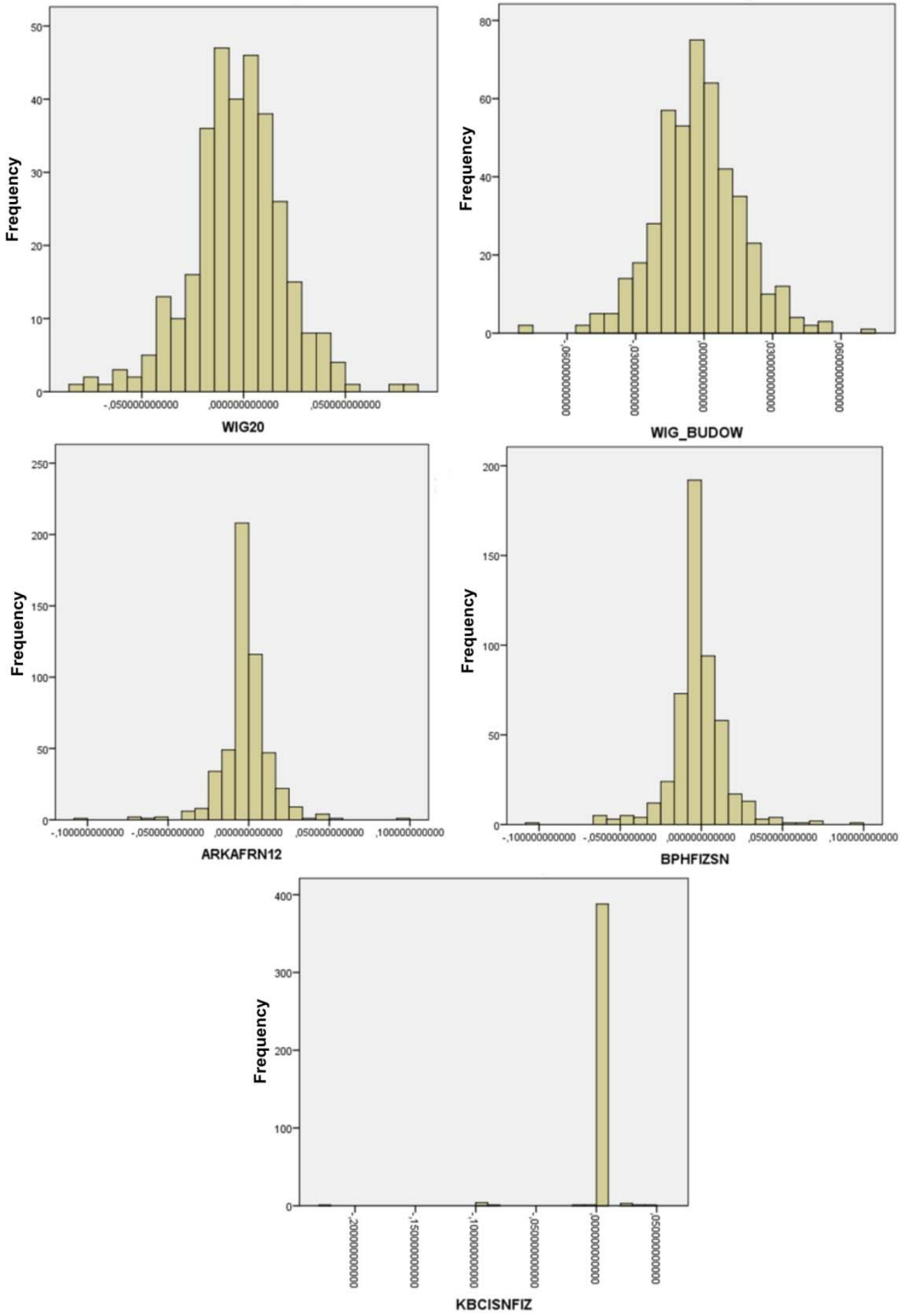

Fig. 2. Distribution of returns in a bear market. Source: own work.

The calculations of risk measures were confirmed by observations concerning skewed distributions. In the first studied period (bull market), standard deviation is greater than semideviation. This relationship changes after the trend shifts. Both calculations for an expected portfolio (for which risk is being forecasted) and an actual portfolio (for which risk was calculated based on actual data recorded after the portfolio had been created) showed that the use of semideviation may expose the investors to higher losses. This is shown by a lower daily rate of return (Table 2). Importantly, this rate of return is only marginally lower, by $0.003 \%$. Thus, this result may not be thought of as fully convincing.

Even though the main hypothesis may be deemed to have been positively verified, one should be 
cautious not to draw too far-fetched conclusions. An approach based on analysis of downside deviations of returns should not be completely rejected. Such an approach may be adequate, but at a time of shifting market trends it would be safer to measure risk by means of all types of return deviations from the expected rates. Additionally, it should be stressed that the created portfolio does not correspond to a real market situation, as one can hardly suppose that any investor would carry out only one analysis over a period of two years. Taking into consideration the changes in risk over time, investors would probably conduct an analysis much earlier, identifying a trend change (which implies the need to perform an additional analysis of investment risk). Therefore, one should consider extending the analysis by changing the methodology of risk calculation. The data could also be extended by considering direct investments in real estate, such as the index published by the National Bank of Poland. Applying these amendments would provide a possibility for further research.

Table 2

Expected and realized portfolios optimized on the basis of either standard deviation or semideviation

\begin{tabular}{|c|c|c|c|c|c|}
\hline & WIG20 & $\begin{array}{l}\text { WIG- } \\
\text { CONSTRUCT }\end{array}$ & ARKAFRN12 & BPHFIZSN & KBCISNFIZ \\
\hline \multicolumn{6}{|l|}{ Bull market 2006-2007 } \\
\hline Mean daily rate of return & $0.135 \%$ & $0.267 \%$ & $0.077 \%$ & $0.033 \%$ & $0.018 \%$ \\
\hline Standard deviation & $1.477 \%$ & $1.675 \%$ & $1.373 \%$ & $1.434 \%$ & $1.983 \%$ \\
\hline Standard semideviation & $0.806 \%$ & $0.958 \%$ & $0.865 \%$ & $0.889 \%$ & $1.081 \%$ \\
\hline \multicolumn{6}{|l|}{ Bear market 2007-2009 } \\
\hline \multirow[t]{2}{*}{ Mean daily rate of return } & & & & & \\
\hline & $0.304 \%$ & $-0.293 \%$ & $-0.081 \%$ & $-0.114 \%$ & $-0.120 \%$ \\
\hline Standard deviation & $2.306 \%$ & $1.987 \%$ & $1.592 \%$ & $1.820 \%$ & $1.478 \%$ \\
\hline Standard semideviation & $9.606 \%$ & $5.086 \%$ & $3.422 \%$ & $4.799 \%$ & $6.943 \%$ \\
\hline \multicolumn{6}{|c|}{ Bull market - portfolio constructed based on expected data } \\
\hline Percentage composition & $0.000 \%$ & $82.761 \%$ & $17.239 \%$ & $0.000 \%$ & $0.000 \%$ \\
\hline Standard deviation & & & $1.440 \%$ & & \\
\hline Rate of return for deviation & & & $0.235 \%$ & & \\
\hline Percentage composition & $0.000 \%$ & $84.219 \%$ & $15.781 \%$ & $0.000 \%$ & $0.000 \%$ \\
\hline Standard semideviation & & & $0.834 \%$ & & \\
\hline $\begin{array}{l}\text { Rate of return for } \\
\text { semideviation }\end{array}$ & & & $0.237 \%$ & & \\
\hline \multicolumn{6}{|c|}{ Bear market - portfolio constructed based on actual data } \\
\hline Percentage composition & $0.000 \%$ & $82.761 \%$ & $17.239 \%$ & $0.000 \%$ & $0.000 \%$ \\
\hline Standard deviation & & & $1.704 \%$ & & \\
\hline Rate of return for deviation & & & $-0.256 \%$ & & \\
\hline Percentage composition & $0.000 \%$ & $84.219 \%$ & $15.781 \%$ & $0.000 \%$ & $0.000 \%$ \\
\hline Standard semideviation & & & $1.095 \%$ & & \\
\hline $\begin{array}{l}\text { Rate of return for } \\
\text { semideviation }\end{array}$ & & & $-0.259 \%$ & & \\
\hline
\end{tabular}

Source: own work.

\section{Summary and conclusions}

None of the analyzed return distributions was a normal distribution. Portfolio analysis confirmed (perhaps not very forcefully, but effectively in light of other results) that estimating risk using standard semideviation may lead to risk underestimation at a time of a market downturn. Theoretically, measuring risk by means of standard semideviation should be appropriate if financial data always had a left-skewed distribution. However, the fact that data may reveal a right-skewed distribution during a bull market (and a left-skewed distribution during a bear market) seems to have been overlooked. Thus, risk calculation during a bull market will not prepare investors for what may 
happen after the trend shifts. However, in the long term, data do remain left-skewed, and in such a situation semideviation may be considered an appropriate measure. The presented study is a contribution to the discussion on measures of risk. Even though there are not enough data and the market is too shallow for the results to provide a final answer, the study does reveal some issues that should be taken into account in the decision-making process.

\section{Bibliography}

Atwood, J., 1985, Demonstration of the Use of Lower Partial Moments to Improve Safety-First Probability Limits, American Journal of Agricultural Economics, Vol. 67, No. 4, pp. 787-793.

Bigman, D., 1996, Safety-First Criteria and Their Measures of Risk, American Journal of Agricultural Economics, Vol. 78, No. 1, pp. 225-235.

CHENG, P., 2005, Asymmetric Risk Measures and Real Estate Returns, The Journal of Real Estate Finance and Economics, 30:1, pp. 89-102.

COOPER, I., PRIESTLEY, R., 2009, Time-Varying Risk Premiums and the Output Gap, Review of Financial Studies, 22, 7, s. 2801-2833.

Ferson, W., KAndel, S., Stambaugh, R., 1987, Tests of Asset Pricing with Time-Varying Expected Risk Premiums and Market Betas, Journal of Finance, 42, 2, s. 201-220.

HaRlow, W.V., RAO, R.S., 1989, Asset Pricing in a Generalized Mean-Lower Partial Moment Framework: Theory and Evidence. Journal Of Financial \& Quantitative Analysis, 24(3), pp.285-311.

KUCHARSKA - STASIAK, E., 2006, Ryzyko inwestowania na rynku nieruchomości, Studia i Materiały Towarzystwa Naukowego Nieruchomości, red. nauk. Źróbek, S., vol. 14, nr 1, Olsztyn, pp. 109-122.

MARKOWITZ H., 1959, Portfolio Selection - Efficient Diversification of Investments, JOHN WILEY \& SONS, New York.

MARKOWITZ, H. M., 1952, Portfolio Selection, Journal of Finance, 7 (1), pp. 77-91.

RoY, A.D., 1952, Safety First and the Holding of Assets, Econometrica, Vol. 20, No. 3, pp. 431-449.

SING, T.F., Ong, S.E., 2000, Asset Allocation in a Downside Risk Framework, Journal of Real Estate Portfolio Management, vol. 6, no. 3, pp. 213-223.

SIVITANIDES, P.S., 1998, A Downside-Risk Approach to Real, Journal of Real Estate Portfolio Management, vol. 4, no. 2, pp. 159-168.

TARCZYŃSKI, W., MOJSIEWICZ, M., 2001, Zarządzanie ryzykiem, POLSKIE WYDAWNICTWO EKONOMICZNE, Warszawa.

TSE, K., UPPAL, J., 1993, Downside risk and investment choice, Financial Review, 28(4), pp. 585-605.

WOLSKI, R., ZALECZNA, M., 2011, The real estate investment of insurance companies in Poland, Journal of Property Investment \& Finance, 29, 1, pp. 74-82. 